\title{
Preservation of industrial heritage
}

\author{
S. Niederhagemann \\ Deutsches Bergbau-Museum [DBM], \\ Informationssysteme Am Bergbaumuseum 28, Germany
}

\begin{abstract}
At least since the admission of the Völklingen Ironworks into the UNESCO list of world heritage in 1994, the industrial care of monuments is beyond dispute in Germany. Industrial buildings are however regarded regionally very differently. Due to numerous characteristics the rehabilitation and conservation of industrial heritage has different requirements than the classic monument preservation. This paper is dedicated to these special cases of human heritage. It will give a short overview about the most essential differences to the common care of monuments and sites.
\end{abstract}

Keywords: industrial heritage, rehabilitation.

\section{Introduction}

Architectural monuments are structural facilities which are important for the history of humans, cities and settlements or for the development of the work and production conditions. There must be artistic, scientific, traditional or urban reasons for their preservation [1].

Technical monuments are evidence of the material culture of our ancestors. They supply descriptive information to us about the work, social and technology history. For very old manufacturing plants this is appreciated world-wide. The worthiness of protecting ancient mines and smelting places is questioned but are no less important than medieval mills and hammer works [2].

\section{Characteristics}

The work with industrial heritage contains special challenges. During the preservation of industrial buildings the controller is often faced with an enormous extent of work. The provided budget permits mostly only a gradual 
and very economic procedure. Differently to the representative buildings, the preservation desire is not always pronounced to all the participants in the same way. Even with landscape-shaping objects with high social and economic relevance the acceptance of some technical plants is often less marked due to their unconventional aesthetics.

Industrial plants are more than other constructions limited in time. Production processes change and if the buildings cannot be adapted they have to disappear. The durability of the constructions was laid out accordingly. The preservation of industrial heritage is therefore sometimes the result of coincidences or dereliction of demolition work.

During the industrial production process contamination is not always preventable. The complete removal of hazardous substances is not always financially economic. Alternatively the contamination can be combined or the access to dangerous areas must be prevented.

Industrial plants are specialized to a certain working process. The alternative uses of some constructions are sometimes badly limited. On the other hand the spectrum of new use possibilities on industrial heritage is wider because there are no ethical aspects to be considered.

\section{Documentation}

Different from the representative buildings the rehabilitation of industrial heritage is made after a long period of quiescence. The shutdown normally takes place without any idea of a new use. A lot of documents get lost because in the interim period between new and old use nobody feels responsible for it. Therefore the documentation and investigation of the plant before the start of any measurement plays an important role. Apart from pure geometry the originality and the still existing equipment are to be evaluated. The extent and inaccessibility of the plant are difficulty in many cases. For the description of the test results, planning and the mass determination a geometrical illustration is always needed. The needed level of detail varies from simple patterns to deformation-fair measurements.

A complete building recording needs investigations and documentations of geometry, materials, use, building history, construction, security and a conservatory evaluation. For investors economy investigations are also important. With the building admission a technically clearly defined question is helpful. Results differ whether the question is if a plant can be conserved or how a plant can be conserved.

In order to receive the general comprehensibility of the documentations is it on the one hand important to keep with international standards and also to record the documentation in a way in order to make results comparable and replicable.

Often the obligation is neglected for the documentation of the accomplished measures. On the one hand such collections serve for the evaluation of rehabilitation success; on the other hand they are necessary to estimate the originality of the building. 


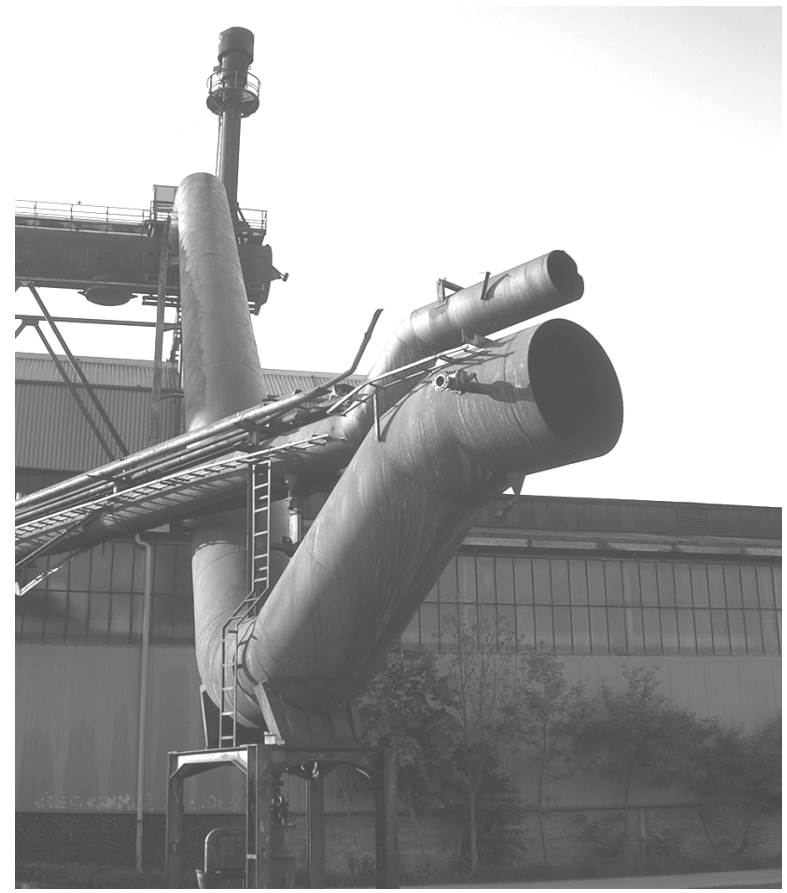

Figure 1: Where to stop the preservation? What must be documented?

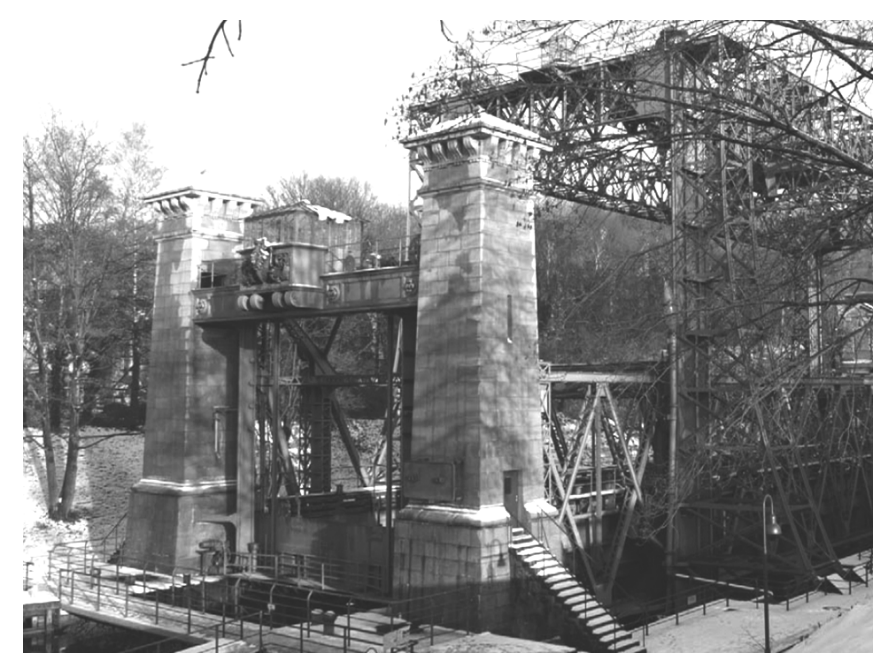

Figure 2: Ship canal lift Henrichenburg extremely rare case of a conversation of an industrial site to an industrial museum without any period of quiescence. 
A complete building recording needs investigations and documentation of geometry, materials, use, building history, construction, security and a conservatory evaluation. For investors economy investigations are also important. With the building admission a technically clearly defined question is helpful. Results differ whether the question is if a plant can be conserved or how a plant can be conserved.

In order to receive the general comprehensibility of the documentations it is important to be keep within international standards and also to record the documentation way in order to make results comparable and replicable.

Often the obligation for documentation of the accomplished measures is neglected, but such collections serve the evaluation of rehabilitation success and it is necessarily to estimate the originality of the building.

Sometimes there is a disagreement about the responsibility for the documentation of building heritage. Frequently all participants make their own documentation and contradictions appear. After project conclusion often only a few results are permanently conserved. These documents are however important for later measures in the sense of recording a damaged development for example.

With a good documentation-management expansive repetition investigations can be avoided. In the age of digital systems the archiving of such data has its difficulties but is much easier than maintaining extensive paper archives.

\section{New uses}

Before start of rehabilitation works the purposes of all measurement has to be defined. The aim should be defined considering the damaged state and the distinctive feature of the monument.

Rehabilitation works and potentialities of use stand in reciprocal effect to each other. Use concepts can eliminate rehabilitation measurements as well as necessitate them. This is also valid the other way around. A new use must not stand in dissent to the distinctive feature of the monument.

As at other monuments, the interventions in industrial heritage substance should be as less as possible and reversible. Temporary uses especially must not eliminate traces of the past.

The classical case of a new use after an active production phase is surely the industrial museum. For this only a few interferences are necessary and the use benefits with an extensive and detailed preservation of the inventory.

Industrial museums usually need benefits, which often are applied by private initiatives or public institutions, [3]. The number of sustainable industrial museums is however smaller than those of the industrial monuments worth protecting. Therefore alternative strategies must be developed.

When for the moment no active use can be found for a monument then it still can be just a memorial or landmark, $[4,5]$. This is not always the worst decision. Maybe later on somebody finds a way for a sustainable use. In some cases the memorial has been kept to be the symbol of a new economy or business which has been developed around on the brown fields. But even if this is the cheapest solution some money for consolidation and enclosure is needed. 


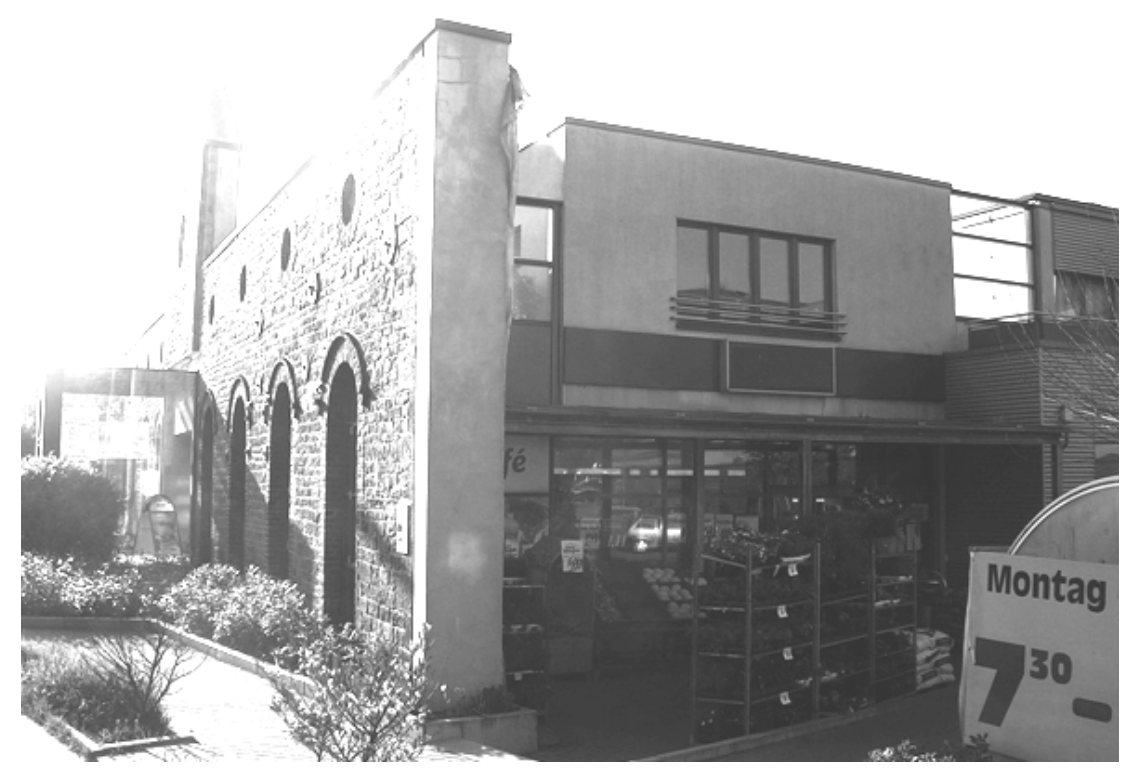

Figure 3: $\quad$ Is this still an industrial monument?

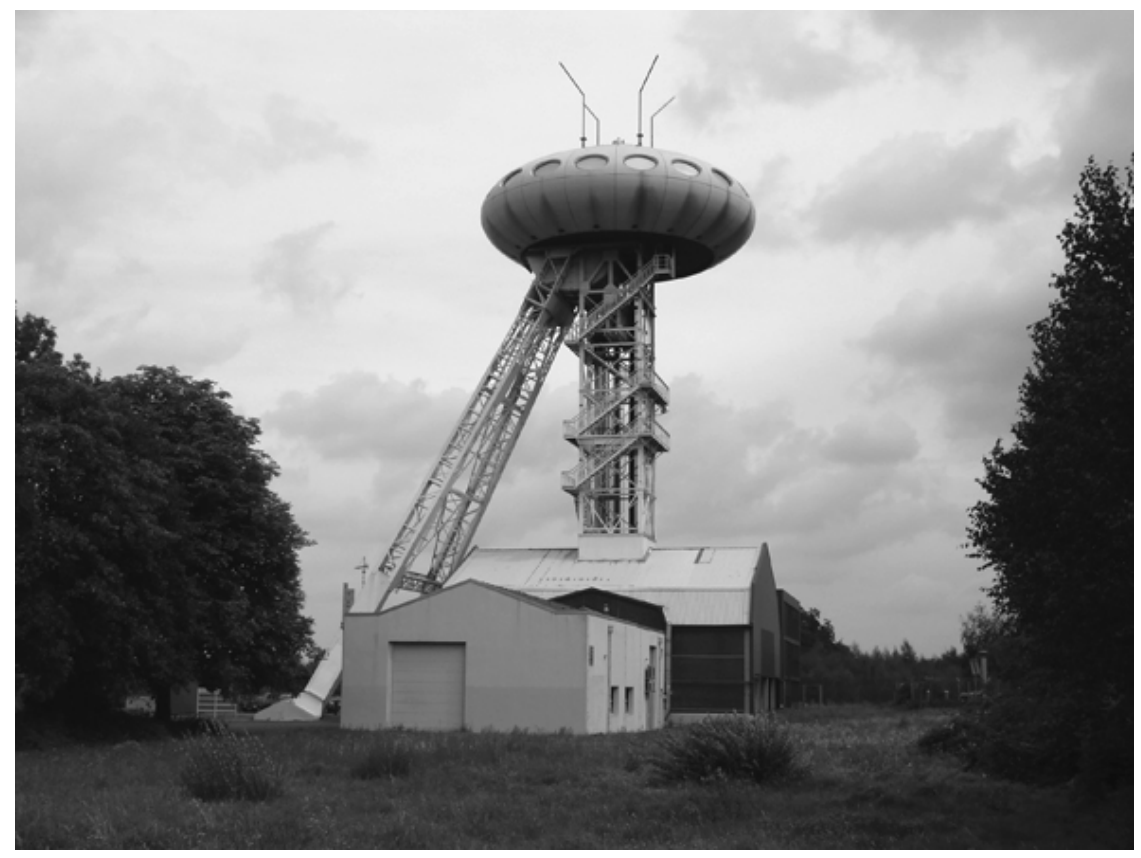

Figure 4: Adaptions for new uses are always needed, but how far can we go? 
The inner part of heritage buildings particularly is completely evacuated and all spurs are removed in order to give spaces for a new inner structure. Sometimes only the street façade has been kept. This method has risks in that the building cannot be understood anymore and that it loses its relevance. Only if the relevance of the heritage is restricted on the façade can this method be practicable.

Even silhouettes can be industrial heritage. The historic blast furnaces silhouette of World heritage Völklingen Ironworks has been reconstructed.

\section{Conclusion}

The conservation and rehabilitation of industrial heritage is a special section of cultural heritage management. The work differs because of, for example, dimensions, contamination and requirements for new uses. The industrial heritage plays an important role in the scene of our monuments and sites today. Despite the difficulties the industrial culture should preserved with the same care as the common objects. Maybe they tell us more about our history than palaces or churches.

\section{References}

[1] Wirtz, Rainer: Entsorger des Fortschritts: Erinnerte Industriekultur/Rainer Wirtz - Konstanz : UVK, Univ.-Verl. Konstanz, 2001

[2] Kühne, Günther, Technische Denkmäler (flyer), hrsg. Deutsches Nationalkomitee für Denkmalschutz, Bonn, oh. Jh. ang.

[3] Karabaic, Milena: Das Industriedenkmal als Museum. Struktur, Konzept und Perspektive am Beispiel des Rheinischen Industriemuseums, in: Brüggerhoff, Stefan; Farrenkopf, Michael; Geerlings, Wilhelm (editor), Montan- und Industriegeschichte S. 563-586, 2006

[4] Slotta, Rainer: Einführung in die Industriearchäologie, 1982

[5] Slotta, Rainer: Technische Denkmäler in der Bundesrepublik Deutschland, 1975 